\title{
Introduction-Indian Media in the Platform Economy
}

\author{
Adrian Athique 1 \\ THE UNIVERSITY OF QUEENSLAND \\ a.athique [AT] uq.edu.au
}

\begin{abstract}
The incumbent Government of India has staked a significant stock of its political capital in the global positioning of India as both tech-savvy and open. It has made strenuous efforts since 2015 to facilitate the infrastructure necessary for realizing the vision of a "Digital India" with universal access and a fully integrated data infrastructure. For their part, global technology players have also proved receptive to the wider ambitions of Digital India because the core initiatives are clearly intended to deliver the ecosystem for a vast platform economy centered upon digital goods and services. Across the four articles included in this special issue, we have attempted to situate our analysis of India's media platforms within the wider pursuit of a platform economy and also within the histories, structures, markets, geographies, and aesthetics of Indian audiovisual culture. In pursuing these aims, we have benefited greatly from an ongoing dialogue with valued friends and colleagues currently working on topics across the breadth of India's platform economy. We look forward to rich and continuing discussions as we progress further into the age of platforms.
\end{abstract}

Keywords: Media Platforms; India; Platform Economy; Indian Media; Digital Media and Society

The incumbent Government of India has staked a significant stock of its political capital in the "global positioning" of India as both "tech-savvy" and "open." It has made strenuous efforts since 2015 to facilitate the infrastructure necessary for realizing the vision of a "Digital India" with universal access and a fully integrated data infrastructure. The high rhetoric of "Digital India" is founded upon the biometric architecture of the Aadhaar platform, the world's largest and most ambitious "mechanism of 'legibility'," which, in turn, supports the further ambition of the "India Stack" and the realization of a transactional economy. In all respects, the state in India remains a key interest in incubating the platform economy, functioning as an orchestrator and an instrument in shaping market norms, and acting as a 
seller of bandwidth and a procurer of infrastructural development. In the international race to harness "smart" technologies for sustainable cities and the "fourth industrial revolution," the Government of India has provided incentives for a range of domestic start-ups while assiduously courting Silicon Valley giants on technology transfers and forging systemic partnerships with India's leading business houses to provide the necessary investments in digital infrastructure. ${ }^{3}$

In important ways, the US\$17 billion Digital India program became feasible only because the mobile telecom boom in the 2000s had already brought both India's major business houses and multinational players into a commanding position in the overall media economy. ${ }^{4}$ The recent entry of Reliance Industries, and US\$42 billion of investment, into that sector has led to consolidation of just two local players, Reliance Jio and Airtel, plus the transnational tie-up between UK Vodaphone and Idea dominating the communications layer. For their part, global technology players have also proved receptive to the wider ambitions of Digital India because the core initiatives are clearly intended to deliver the ecosystem for a vast platform economy centered upon digital goods and services. In the transactional layer, domestic entrepreneurs have been developing digital start-ups and platform brands across a broad range of marketplaces and services. Indian platforms such as Flipkart, Ola, and Paytm have attracted multiple rounds of funding, initially from ambitious technology banks based elsewhere in Asia (such as Alibaba, SoftBank, and Mediatek) and, more recently, from major US players (such as Amazon, Walmart, and Microsoft). Efforts by Facebook to set up proprietary systems via the Basics program in 2016 and the tussle between Amazon and Walmart in 2018 for a controlling stake in India's e-commerce markets clearly reflect India's interpolation within the global digital economy, as does the recent announcement of India as a test bed for Facebook's Libra currency experiment.

Intensifying competition between the multinational "platform giants" across India's digital marketplaces provides clear evidence of international interests in the potentials of a platform economy in India. ${ }^{5}$ It is equally well known that Twitter is providing India with its political soapbox. ${ }^{6}$ Thus, beyond the technical ecosystem, the commercial ecosphere appears to be evolving into a definite form. Google already dominates the digital advertising market in India as a near monopoly. Against this backdrop, India's plentiful start-ups must also contend with the consequences of India's own vast telecom companies moving into content provision as a means of driving their own expansion (as with Reliance Industries launching Jio TV and Jio Music, and acquiring Saavn, via its Jio mobile network). ${ }^{7}$ Increasingly, as we begin to comprehend the mobility and monetization of both content and users across an interlinked ecology of platforms, we are prompted to consider the consequences of internet consolidation for the media economy. ${ }^{8}$ Notably, for readers of this journal, we have to ponder the subsumption of erstwhile "media industries" under the imperium of providers of digital infrastructure.

As a starting point, I use the instance of the emporium in the first article of this special section as both a structural analogy and a metaphor for the platform economy. My immediate motivation is to "disrupt disruption" as a material reality, explanatory framework, or rationale for the platform economy. Emerging out of a productive discussion with Tom O'Regan (on the historical antecedents of retail platforms), and my recent collaboration with Vibodh 
Parthasarathi (on distinctive market forms in the Indian media economy), my contribution here attempts to reframe critiques of platform capitalism by tracing the evolutionary pathways that are converging in India's platform economy. The argument included here was developed through rich and rewarding interactions with colleagues at workshops hosted by the platform media initiative at the University of Queensland in August 2018 and the Platform Capitalism, Communication and Culture in South Asia symposium held at Curtin University in June 2019, and supported by the South Asian Studies Association of Australia.

Evidently, one of the critical pathways to the platform economy is the long-term evolution of India's media economy and the various industries that operate within it. In this domain, parallel to the inroads being made by the behemoths of Silicon Valley and the advent of various app brands and services, a range of Indian media businesses now operate their own platform services. Notable examples of "legacy to digital" remediation include STAR TV (Hot Star), Sony (SonyLIV), ZEE (OZeeTV), and EROS (Eros Now) in film and television. A range of independent media platforms have also emerged, such as TVF Play and Yupp TV in television and Hungama, Saavn, and Gaana in music. ${ }^{9}$ These media platforms are contesting the media marketplace against larger players investing in entire ecospheres (such as Amazon Prime and Jio). Focusing on recent developments in over-the-top (OTT) video services for this special section, Scott Fitzgerald traces the evolution of this segment in India, providing comparison with the prevailing business logics of OTT in the West. ${ }^{10}$ Fitzgerald succinctly identifies the major actors, product offerings, and regulatory conditions that constitute the distinctive features of the OTT market in India. Fitzgerald recalls the regulatory debates on media imperialism that dominated the earlier disruption of satellite broadcasting in India and prompts scholars to reconsider those transnational dynamics in a time of platforms.

Elsewhere in the audiovisual sector, and across a wide range of regional and subregional markets, a vast array of India's informal media producers, along with established labels, broadcasters, and journalists, have migrated into the YouTube platform. ${ }^{11}$ This phenomenon has made India one of the largest markets for user-generated content, providing a new means of carriage for a diverse sensorium of popular culture and commentary. This prompts Akshaya Kumar to provide us with an invigorating critical examination of the remediation of informality in the era of platform media. The informal sector in India has always been the exuberant counterpart of India's sanctioned media businesses, driving both the aesthetics and the temper of popular culture in India. As such, it has been simultaneously both the central capacity and the gray economy of sound and image production, and the interaction of this domain with platform architectures is necessarily a central concern in determining the future of popular culture in India. Kumar elucidates the emergence of YouTube as an arbitrage platform for informal media economies, which in turn situates its repository as the archive of the popular across India, channeling a multiplicity of cultures and voices. In this function, the suturing of formal and informal economies via YouTube brings to light its own evolutionary precedent in the era of cassette culture and explicates its recent acquisition of India's T Series, thereby formalizing its alliance with vernacular domains. Nonetheless, Kumar avoids a clumsy diagnosis of popular enclosure by reminding us that the archive of the popular is not the popular itself and that, notwithstanding the status of YouTube as the distribution layer of an expanded present, the energies of the popular in India remain focused on the moment of performance. 
From this simultaneous endurance and expansion of the local, Ramon Lobato and Pradip Sarkar direct us outward into the domain of the Indian diaspora. Just as Fitzgerald reminds us usefully of the trans-territoriality of media platforms, Lobato and Sarkar highlight this larger dynamic in the context of the informal circuits of television distribution. Just as India's home-grown service platforms are already venturing overseas (as with the launch of taxi platform, Ola, in Australia and the United Kingdom in 2018), a number of media platforms have given strategic attention to the potentials of overseas markets. Lobato and Sarkar provide important insights into the blending of formal and informal modes of distribution pursued by Yupp TV, LycaTV, and Jadoo in their attempts to "platformize" the overseas market for audiovisual content among India's vast diaspora. ${ }^{12}$ Here, the critical platform is not the channel or the firm, but rather the device. Lobato and Sarkar explain how the internet protocol television (IPTV) box has come to occupy the gray markets of diasporic media provision in Australia, remediating and replacing the older circuits of playback media and cable services. As a technical innovation that circumvents the boundaries of formal distribution, the IPTV box gives carriage to an alternative geography of informal distribution that arises from the mobility of audiences and mutability of data flows. Providing a compelling counterpoint to Kumar's account of the efflorescence of India's regional media, Lobato and Sarkar clearly demonstrate how interventions in the distribution layer are harnessing platforms to the dispersed geographies of television.

Across the four articles included in this special issue, we have attempted to situate our analysis of India's media platforms within the wider pursuit of a platform economy and also within the histories, structures, markets, geographies, and aesthetics of Indian audiovisual culture. In pursuing these aims, we have benefited greatly from an ongoing dialogue with valued friends and colleagues currently working on topics across the breadth of India's platform economy. Thus, in the domain of television, we would like to acknowledge the insights of Vibodh Parthasarathi and Ishita Tiwary. Engaging with the media economy more broadly, we would like to thank Usha Rodrigues, Hrishikesh Arvikar, and Ravi Sundaram for their contributions to the discussion. For their observations and analysis of the wider ecology of platforms in India, we would like to acknowledge important contributions from Shishir K. Jha, Vigneswara Ilavarasan, Pradip Thomas, Nupur Choudry, Pawan Singh, Harsh Taneja, Chetna Monga, and Amit Rai. We would also like to thank Tom O'Regan, Michael Keane, and Dwayne Winseck for sharing their thoughts on comparative approaches to platforms in India. As I write this in Delhi in October 2019, I would also like to thank the Department of Management Studies, IIT Delhi, for hosting my lecture series on India's platform economy, along with the IIT students who are generously sharing their expertise and enthusiasm for this enquiry. Above all, the encouragement and support of Kevin Sanson and the editorial team at Media Industries Journal has been critical in bringing these initial papers to readers, and I look forward to rich and continuing discussions as we progress further into the age of platforms.

\footnotetext{
${ }^{1}$ Adrian Athique is programme leader in Cultural Studies at the Institute for Advanced Studies in the Humanities (IASH). Adrian's research interests focus on the social, cultural, and economic implications of digital technologies and the evolution of media cultures in Asia. He is the author of several books, including The Multiplex in India: A Cultural Economy of Urban Leisure (Routledge, 2010, with Douglas Hill),
} 
Indian Media (Polity, 2012), Digital Media and Society (Polity, 2013), and Transnational Audiences: Media Reception on a Global Scale (Polity, 2016). Adrian is also editor of the journal Media International Australia, the OUP series: Media Dynamics in South Asia, and The Indian Media Economy (2 Vols, Oxford University Press, 2018, with Vibodh Parthasarathi and SV Srinivas) and Digital Transactions in Asia (Routledge, 2019, with Emma Baulch).

${ }^{2}$ See Shankar Aiyar. Aadhaar: A Biometric History of India's 12-Digit Revolution (Delhi: Westland, 2017).

${ }^{3}$ Pradip Thomas. The Politics of Digital India (New Delhi: Oxford University Press, 2019).

${ }^{4}$ See Douglas Hill and Adrian Athique. "The Role of Off Shore Financial Centres in Indian telecoms," in The Indian Media Economy: Industrial Dynamics and Cultural Adaptation, vol. 1, ed. Adrian Athique, Vibodh Parthasarathi, and S. V. Srinivas (New Delhi: Oxford University Press, 2018), 66-92.

${ }^{5}$ See Dwayne Winseck. "The Geopolitical Economy of the Global Internet Infrastructure," Journal of Information Policy 7 (2017): 228-67.

${ }^{6}$ Usha M. Rodrigues and Michael Niemann. "Social Media as a Platform for Incessant Political Communication: A Case Study of Modi's "Clean India" Campaign," International Journal of Communication 11 (2017): 23.

${ }^{7}$ Rahul Mukherjee. "Jio Sparks Disruption 2.0: Infrastructural Imaginaries and Platform Ecosystems in 'Digital India'," Media, Culture E Society 41 (2, 2019): 175-95.

${ }^{8}$ Shishir K. Jha and Niraj Mankund. "Examining Digital Competencies Within The Entertainment Industry," in The Indian Media Economy: Market Dynamics and Social Transactions, vol. 2, ed. Adrian Athique, Vibodh Parthasarathi, and S. V. Srinivas (New Delhi: Oxford University Press, 2018), 80-98.

${ }^{9}$ Gregory D. Booth. "A Long Tail in the Digital Age: Music Commerce and the Mobile Platform in India," Asian Music 48 (1, 2017): 85-113.

${ }^{10}$ Scott Fitzgerald. "Over-the-Top (OTT) Video Services in India: Media Imperialism After Globalization," Media Industries Journal, this issue, 6 (2, 2019).

${ }^{11}$ See Akshaya Kumar. "Informality in the Time of Platformization," Media Industries Journal, this issue,6 $(2,2019)$, and S. V. Srinivas. "Politics in the Age of YouTube: Degraded Images and Small Screen Revolutions," In Asian Video Cultures: In the Penumbra of the Global, ed. Joshua Neves and Bhaskar Sarkar (Durham, NC: Duke University Press, 2017), 217-39.

12 Ramon Lobato. "The OTT TV Box as a Diasporic Media Platform," Media Industries Journal, this issue, $6(2,2019)$.

\section{Bibliography}

Aiyar, Shankar. Aadhaar: A Biometric History of India's 12-Digit Revolution. Delhi: Westland, 2017.

Booth, Gregory D. "A Long Tail in the Digital Age: Music Commerce and the Mobile Platform in India." Asian Music 48, no. 1 (2017): 85-113. 
Fitzgerald, Scott. "Over-the-Top (OTT) Video Services in India: Media Imperialism After Globalization." Media Industries Journal. This issue.

Hill, Douglas and Athique, Adrian. "The Role of Off Shore Financial Centres in Indian Telecoms." In The Indian Media Economy: Industrial Dynamics and Cultural Adaptation, vol. 1, edited by Adrian Athique, Vibodh Parthasarathi and S. V. Srinivas, 66-92. New Delhi: Oxford University Press, 2018.

Jha, Shishir K. and Mankund, Niraj. "Examining Digital Competencies Within The Entertainment Industry." In The Indian Media Economy: Market Dynamics and Social Transactions, vol. 2, edited by Adrian Athique, Vibodh Parthasarathi and S. V. Srinivas, 80-98. New Delhi: Oxford University Press, 2018.

Kumar, Akshaya. "Informality in the Time of Platformization." Media Industries Journal. This issue.

Lobato, Ramon. "The OTT TV Box as a Diasporic Media Platform." Media Industries Journal. This issue.

Mukherjee, Rahul. "Jio Sparks Disruption 2.0: Infrastructural Imaginaries and Platform Ecosystems in 'Digital India'." Media, Culture E Society 41, no. 2 (2019): 175-95.

Rodrigues, Usha M., and Michael Niemann. "Social Media as a Platform for Incessant Political Communication: A Case Study of Modi's "Clean India" Campaign." International Journal of Communication 11 (2017): 23.

Srinivas, S. V. "Politics in the Age of YouTube: Degraded Images and Small Screen Revolutions." In Asian Video Cultures: In the Penumbra of the Global, edited by Joshua Neves and Bhaskar Sarkar, 217-39. Durham, NC: Duke University Press, 2017.

Thomas, Pradip. The Politics of Digital India. New Delhi: Oxford University Press, 2019.

Winseck, Dwayne. "The Geopolitical Economy of the Global Internet Infrastructure." Journal of Information Policy 7 (2017): 228-67. 